\title{
Effect of Daily Physical Education on Physical Fitness in Elementary School Children
}

\author{
Klaus Greier ${ }^{1,2 *}$, Clemens Drenowatz ${ }^{3}$, Gerhard Ruedl1, \\ Martin Kopp1, Martin Burtscher ${ }^{1}$, Carla Greier ${ }^{1}$ \\ ${ }^{1}$ Department of Sport Science, University Innsbruck, Innsbruck, Austria \\ ${ }^{2}$ Division of Physical Education, Private University of Education (KPH-ES), Stams, Austria \\ ${ }^{3}$ Division of Physical Education, University of Education (PHOOE), Linz, Austria \\ Email: *nikolaus.greier@kph-es.at
}

How to cite this paper: Greier, K., Drenowatz, C., Ruedl, G., Kopp, M., Burtscher, M., \& Greier, C. (2020). Effect of Daily Physical Education on Physical Fitness in Elementary School Children. Advances in Physical Education, 10, 97-105.

https://doi.org/10.4236/ape.2020.102009

Received: April 7, 2020

Accepted: May 8, 2020

Published: May 11, 2020

Copyright $\odot 2020$ by author(s) and Scientific Research Publishing Inc. This work is licensed under the Creative Commons Attribution International License (CC BY 4.0).

http://creativecommons.org/licenses/by/4.0/

\begin{abstract}
Background: Increased screen time and change in the built environment have contributed to a decline in physical activity (PA) in children and adolescents over the last several decades, which also contributed to a decline in physical fitness. The purpose of the present study was to examine the influence of daily school-based physical activity on the development of physical fitness in elementary school children. Methods: A total of 230 elementary school children $(53.9 \%$ male) from 10 elementary schools in Tyrol, Austria completed the German motor test at the beginning of grade 1 (October 2017) and at the end of grade 2 (June 2019). Five schools were randomly assigned to an intervention that provided daily physical education (PE) while the control group continued with $3 \mathrm{PE}$ classes per week as specified by the curriculum. Differences in the development of physical fitness between students in the intervention and control schools were examined via ANCOVA, adjusting for baseline fitness. Results: Children in the intervention schools displayed significantly higher improvements in the 6-minute run, $20 \mathrm{~m}$ sprint, sit ups and backward balance $(p<0.01)$ compared to their peers in the control schools. No significant differences were observed in the development of standing long jump, sideways jumping, push-ups and stand and reach. Discussion: The present study indicates beneficial effects of daily PE on physical fitness, particularly regarding endurance, core strength, speed and balance in Tyrolean elementary school children. Accordingly, daily PE appears to be a viable option for the promotion of physical fitness in children.
\end{abstract}

\section{Keywords}

Motor Development, School Children, Motor Skills, Health, Physical Education 


\section{Introduction}

In recent years physical education (PE) teachers have become increasingly concerned about low physical activity (PA) levels and the associated decline in motor performance in schoolchildren (Greier, 2013). Sedentary habits such as watching TV and playing computer games have become increasingly popular and replaced habitual PA (Kaiser-Jovy, Scheu, \& Greier, 2017; Owen, Healy, Matthews, \& Dunstan, 2010; Mathers et al., 2009). Accordingly, a majority of children and adolescents do not achieve the current PA recommendations of at least 60 minutes of moderate-to-vigorous PA per day (Reilly et al., 2004; WHO, 2016). In light of these developments there is also a large number of scientific studies that address the negative aspects of low PA and a sedentary lifestyle (Janssen \& Leblanc, 2010; Houston et al., 2013; Dutra, Kaufmann, Pretto, \& Albernaz, 2015; Burtscher, 2015; Greier et al., 2018). Insufficient PA has been associated with the development of various so-called "sedentary lifestyle disorders", including poor posture, obesity, metabolic disorders, diabetes and diseases of the cardiovascular system (Ferrari et al., 2015; Dutra et al., 2015). In addition to negative health effects, low PA levels have led to a decline in physical fitness and motor performance (Tomkinson, Léger, Olds, \& Cazorla, 2003; Tomkinson \& Olds, 2007; Albon, Hamlin, \& Ross, 2010; Hardy, Barnett, Espinel, \& Okely. 2013; Muellerova et al., 2015; Ruedl, Greier, Kirschner, \& Kopp, 2016; Greier \& Drenowatz, 2018; Greier, Riechelmann, Ruedl, \& Drenowatz, 2019). Even though there is a reciprocal relationship between PA, physical fitness and motor competence, all aspects have been shown to be important modifiable components in health promotion (Myers, Prakash, Froelicher, Partington, \& Atwood, 2002; Bauman, 2004; Ortega, Ruiz, Castillo, \& Sjöström, 2008; Vandorpe et al., 2012; Erfle \& Gamble 2015; Ruedl et al., 2016; Greier \& Drenowatz, 2018).

This applies all the more as motor performance, regardless of a genetic contribution, can strongly be influenced by training of basic motor characteristics (Chiodera et al., 2008; Förster, 2005; Logan et al., 2012; Riethmuller et al., 2009). The necessity for nurturing motor development further emphasizes the need for starting the promotion of motor development at young ages. The primary school years are considered a critical phase for the development of motor competence and physical fitness (Augste \& Künzell, 2015). An increase in sports participation during school hours, including daily opportunities for PA, therefore, should be given special consideration. Current school curricula in Austria, however, mandate only 2 - 3 lessons (50 min each) of PE per week, which provides only limited possibilities to counteract the lack of PA of today's students. Accordingly, the need for daily PA has been repeatedly emphasized (Osterroth, Spang, \& Gießing, 2012). Limited data on this issue, however, is available in Austria and it can only be speculated that a daily PA intervention at school level is associated with increased physical fitness in elementary school children. The aim of the present study, therefore, was to evaluate the effect of a "daily exercise lesson" on the development of physical fitness in Tyrolean primary school children. 


\section{Methods}

A total of 10 elementary schools were randomly selected for participation. Due to the longitudinal nature of the study only first grade students were eligible for participation, resulting in a sample size of 273 children. Parents were informed by letter via the participating schools and provided written informed consent. Students provided oral assent at the time of measurement. All study procedures were approved by the responsible authorities of the schools (State School Council for Tyrol) and the Review Board of the University of Innsbruck (Advisory Board for Ethical Issues in Scientific Research).

Data collection occurred at the beginning of grade 1 (October/November 2017) and at the end of grade 2 (May/June 2019). All schools were localized in rural areas and had comparable socio-ecological conditions. The curriculum of all participating schools required 3 separate classes of PE (50 min each) on three days per week. Schools were randomly assigned to the intervention or served as control schools. The five schools that were assigned to the intervention received two additional PE lessons and thus provided daily activity classes for their students. The five control schools continued the regular PE classes 3 times per week.

All participating students completed the German Motor Test (DMT 6 - 18) (Bös et al., 2009), which also includes anthropometric measurements, at baseline and follow-up. The measurements were taken by exercise science students that were trained in the administration of the DMT6-18 and took place during regular school time in the school gymnasium. Prior to the fitness tests, body height and weight were measured in sportswear without shoes (barefoot). Body height was measured to the nearest $0.1 \mathrm{~cm}$ with a mobile stadiometer $\left(\mathrm{SECA}^{\circledR} 217\right.$; Seca, Germany) and the body weight was measured to the nearest $0.1 \mathrm{~kg}$ with a calibrated scale (SECA ${ }^{\circledR}$ 803; Seca, Germany). Subsequently body mass index was calculated (BMI, $\left.\mathrm{kg} / \mathrm{m}^{2}\right)$.

The German Motor Test (DMT 6 - 18) consists of 8 test items that assess endurance, strength, power, speed, agility, balance and flexibility (Bös et al., 2009). Specifically, students performed a $20 \mathrm{~m}$ sprint, backward balancing, side-to-side jumping, long-distance jump, sit-ups, push-ups, torso bend and 6-minute run with practice trials and measured attempts as specified by the test manual. The tests were administered in random order, except for the 6-minute run, which was completed at the end of the testing session in order to avoid undue fatigue that may affect test results. There was also sufficient rest between the other tests in order to enable students to perform at their maximum abilities.

\section{Statistical Analysis}

Descriptive statistics were calculated and interval scaled data is reported as means with standard deviation; prevalences are shown for nominal data. Change in physical fitness was calculated as follow-up minus baseline at the individual level. Subsequently, ANCOVA, was used to examine differences in change in physical fitness between students in the intervention and control schools, ad- 
justing for baseline values. Statistical analyses were performed with SPSS 26.0 (Armonk, NY, USA) with a significance level of $p \leq 0.05$.

\section{Results}

A total of 230 students (53.9\% male) provided valid data at baseline (fall 2017) and follow-up (spring 2019) with 101 students (52.5\% male) in the intervention group and 129 students (55.0\% male) in the control group. There was no significant sex difference across the two groups and no significant differences in anthropometric characteristics and physical fitness were observed at baseline (Table 1).

Table 1. Baseline characteristics by intervention and sex. Values are Mean \pm SD $(n=230)$.

\begin{tabular}{|c|c|c|c|c|c|c|}
\hline \multirow{2}{*}{ Characteristic } & \multicolumn{3}{|c|}{ Intervention group } & \multicolumn{3}{|c|}{ Control group } \\
\hline & boys & girls & total & boys & girls & total \\
\hline Age & $6.4 \pm 0.5$ & $6.2 \pm 0.4$ & $6.3 \pm 0.5$ & $6.4 \pm 0.5$ & $6.3 \pm 0.4$ & $6.3 \pm 0.4$ \\
\hline Height $(\mathrm{cm})$ & $124.2 \pm 5.5$ & $121.4 \pm 6.0$ & $122.9 \pm 5.9$ & $124.5 \pm 5.6$ & $122.8 \pm 5.2$ & $123.7 \pm 5.5$ \\
\hline Weight (kg) & $24.4 \pm 4.5$ & $23.9 \pm 5.0$ & $24.2 \pm 4.7$ & $25.1 \pm 4.6$ & $24.1 \pm 3.9$ & $24.7 \pm 4.3$ \\
\hline BMI & $15.8 \pm 1.9$ & $16.0 \pm 2.0$ & $15.9 \pm 1.9$ & $16.1 \pm 1.9$ & $15.9 \pm 1.8$ & $16.0 \pm 1.9$ \\
\hline $20 \mathrm{~m}$ sprint $(\mathrm{sec})$ & $4.7 \pm 0.4$ & $4.8 \pm 0.6$ & $4.8 \pm 0.4$ & $4.7 \pm 0.4$ & $4.7 \pm 0.5$ & $4.7 \pm 0.4$ \\
\hline Jumping side-ways (\# in $15 \mathrm{sec}$ ) & $23.4 \pm 6.6$ & $23.9 \pm 6.3$ & $23.7 \pm 6.5$ & $25.5 \pm 5.9$ & $24.9 \pm 6.2$ & $25.2 \pm 6.0$ \\
\hline Standing long-jump (cm) & $115.5 \pm 15.6$ & $110.1 \pm 13.9$ & $112.9 \pm 15.1$ & $118.5 \pm 22.8$ & $108.8 \pm 22.5$ & $114.2 \pm 23.1$ \\
\hline Push-ups (\# in $40 \mathrm{sec}$ ) & $12.4 \pm 3.3$ & $12.3 \pm 3.4$ & $12.4 \pm 3.2$ & $13.2 \pm 3.8$ & $13.1 \pm 3.5$ & $13.2 \pm 3.6$ \\
\hline Sit Ups (\# in $40 \mathrm{sec}$ ) & $16.2 \pm 5.9$ & $16.5 \pm 4.6$ & $16.4 \pm 5.3$ & $18.2 \pm 5.8$ & $16.5 \pm 4.5$ & $17.6 \pm 5.9$ \\
\hline 6-minute run $(\mathrm{m})$ & $837.4 \pm 93.4$ & $800.2 \pm 77.9$ & $819.7 \pm 87.9$ & $850.3 \pm 117.4$ & $792.7 \pm 128.8$ & $824.5 \pm 125.5$ \\
\hline Balancing back-wards (steps) & $28.5 \pm 8.9$ & $29.4 \pm 10.1$ & $28.9 \pm 9.4$ & $26.7 \pm 9.4$ & $31.9 \pm 8.9$ & $29.1 \pm 9.6$ \\
\hline Stand-and-Reach $(\mathrm{cm})$ & $-1.4 \pm 5.1$ & $0.4 \pm 5.7$ & $-0.5 \pm 5.4$ & $-0.8 \pm 5.6$ & $0.7 \pm 6.6$ & $-0.1 \pm 6.0$ \\
\hline
\end{tabular}

The average improvement in physical fitness throughout the observation period was generally more pronounced among students in the intervention classes. Significant differences were observed in the $20 \mathrm{~m}$ sprint, balancing backwards, sit-ups and 6-minute run $(p<0.01)$. No significant differences between intervention and control students were observed for the development in push-ups, standing long-jump, jumping sideways and stand-and-reach $(p>0.48)$ (Figure 1 and Figure 2).

\section{Discussion}

The present study examined the effect of a daily physical activity class on the development of physical fitness in elementary school children in Tyrol, Austria. As expected performance on physical fitness tests improved from the first to the second grade, but the improvement was more pronounced in students with daily school-based PE compared to children with only 3 PE lessons per week. The improvement in endurance capacity, speed, core strength and balance was particularly 


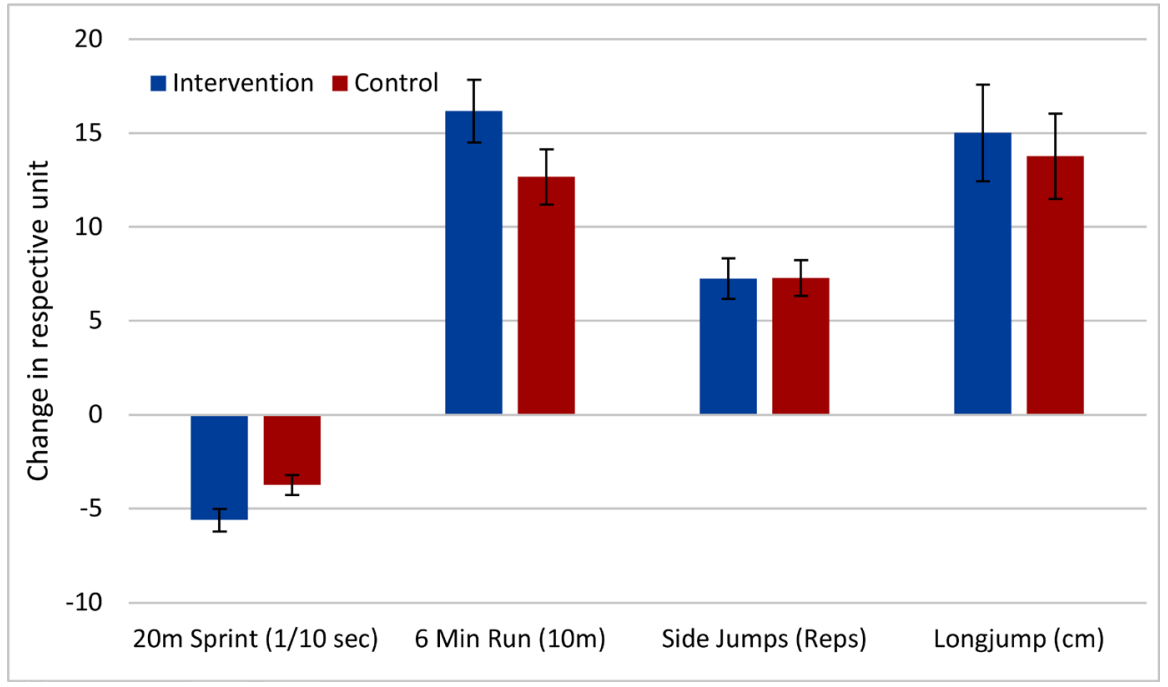

Figure 1. Change in physical fitness from baseline to follow-up for intervention group and control group. Values are Means, adjusted for baseline performance with $95 \%$ CI.

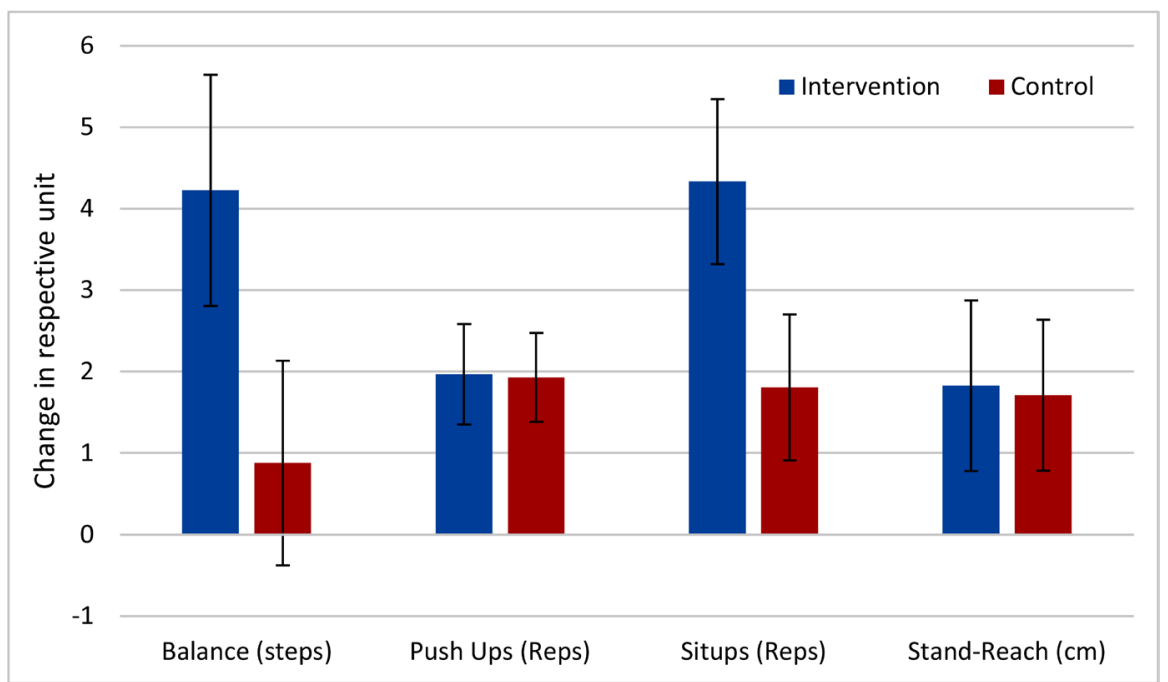

Figure 2. Change in physical fitness from baseline to follow-up for intervention group and control group. Values are Means, adjusted for baseline performance with 95\% CI.

pronounced. No significant differences, on the other hand, were observed for the development of upper body strength, muscular power, agility and flexibility.

Even though low PA in children has been well documented (Guthold et al., 2020), there remains limited research on effect of daily PE lessons. Available research, however, has shown beneficial effects of daily school-based PE on motor development. A 4-year intervention study in German elementary school children, for example, showed a significantly greater improvement in physical fitness with daily PE compared to a control group following the regular curriculum (Obst \& Bös, 1998). A recent study from Sweden also showed that motor skills were significantly better in school children with daily PE compared to their peers (Eriksson \& Karlsson, 2014). This 9-year longitudinal study further showed an improvement in learning skills and school performance with daily PE. Another 
4-year longitudinal study in German elementary school students, on the other hand, did not show any differences in motor and psychological development between students having a daily sports lesson and those receiving the amount of PE specified in the curriculum (Seyda, 2011). Differences in study design and methodology, including age range, school types and observation period, however, limit comparability between studies. Accordingly, it is not possible at this time to provide definitive answers on the effects of daily PE even though the available data indicate beneficial effects of increased school-based PE on motor development as well as cognitive and psychological aspects.

Some limitations of this study, however, should be considered when interpreting the results. It should be pointed out that the study is also still ongoing and the current results present only preliminary findings over the first 2 years. Due school closures in response to the current health situation (COVID-19 pandemic) it is, unfortunately, not possible to perform additional fitness tests this semester, but it is planned to continue the study the next school-year, when participating children are in $4^{\text {th }}$ grade. The relatively short observation period, however, may explain the limited differences in some components of physical fitness in the present study. In addition, it should be considered that the present study only looked at supervised in-school activities and did not consider leisure-time PA or club sports. Further, the additional PE classes were structured similarly to regular PE but there is no information on the specific content covered in these extra classes. The beneficial effects of club sports participation on motor development and physical fitness, however, have been shown in various studies (Greier et al., 2018; Drenowatz, Greier, Ruedl, \& Kopp, 2019; Drenowatz \& Greier, 2019). Club sports, however, may not be accessible to all students. Nevertheless, this aspect should be considered when interpreting the results of this study. The comparable socio-ecological situation of the participating schools and the use of a standardized and validated fitness test battery, on the other hand, are considerable strengths of this study.

\section{Conclusion}

In summary, the results of the present study, together with previous studies, indicate positive effects of daily PE on the development of physical fitness in primary school children. Since only schools can reach all children over a prolonged period of time, daily structured exercise times along with PE could provide a viable option in the promotion of physical fitness at young ages. Given the beneficial association between physical fitness and PA (Drenowatz \& Greier, 2018), this may facilitate higher PA throughout childhood and potentially into adolescence.

\section{Conflicts of Interest}

The authors declare no conflicts of interest regarding the publication of this paper. 


\section{References}

Albon, H., Hamlin, M., \& Ross, J. (2010). Secular Trends and Distributional Changes in Health and Fitness Performance Variables of 10 - 14-Year-Old Children in New Zealand between 1991 and 2003. British Journal of Sports Medicine, 44, 263-269. https://doi.org/10.1136/bjsm.2008.047142

Augste, C., \& Künzell, S. (2015). Longitudinal Study on Health Relevant Behavior in Primary School. German Journal of Sports Medicine, 66, 17-22. https://doi.org/10.5960/dzsm.2014.151

Bauman, A. (2004). Updating the Evidence That Physical Activity Is Good for Health: An Epidemiological Review 2000-2003. Journal of Science and Medicine in Sport, 7, 6-19. https://doi.org/10.1016/S1440-2440(04)80273-1

Bös, K., Schlenker, L., Büsch, D., Lämmle, L., Müller, H. et al. (2009). German Motor Abilities Test 6-18 (DMT6-18). Hamburg: Czwalina.

Burtscher, M. (2015). Körperliche Inaktivität und chronische Erkrankungen. Therapeutische Umschau, 72, 293-301. https://doi.org/10.1024/0040-5930/a000679

Chiodera, P., Volta, E., Gobbi, G., Milioli, M. A., Mirandola, P. et al. (2008). Specifically Designed Physical Exercise Programs Improve Children's Motor Abilities. Scandinavian Journal of Medicine \& Science in Sports, 18, 179-187. https://doi.org/10.1111/j.1600-0838.2007.00682.x

Drenowatz, C., \& Greier, K. (2018). The Role of Motor Competence in the Promotion of Physical Activity and Healthy Body Weight in Youth. Annals of Pediatrics \& Child Health, 6, 1155.

Drenowatz, C., \& Greier, K. (2019). Cross-Sectional and Longitudinal Association of Sports Participation, Media Consumption and Motor Competence in Youth. Scandinavian Journal of Medicine \& Science in Sports, 29, 854-861.

https://doi.org/10.1111/sms.13400

Drenowatz, C., Greier, K., Ruedl, G., \& Kopp, M. (2019). Association between Club Sports Participation and Physical Fitness across 6- to 14-Year-Old Austrian Youth. International Journal of Environmental Research and Public Health, 16, 3392. https://doi.org/10.3390/ijerph16183392

Dutra, G., Kaufmann, C., Pretto, A., \& Albernaz, E. (2015). Television Viewing Habits and Their Influence on Physical Activity and Childhood Overweight. The Journal of Pediatrics, 91, 346-351. https://doi.org/10.1016/j.jped.2014.11.002

Erfle, S., \& Gamble, A. (2015). Effects of Daily Physical Education on Physical Fitness and Weight Status in Middle School Adolescents. Journal of School Health, 85, 27-35. https://doi.org/10.1111/josh.12217

Ericsson, I., \& Karlsson, M. (2014). Motor Skills and School Performance in Children with Daily Physical Education in School: A 9-Year Intervention Study. Scandinavian Journal of Medicine \& Science in Sports, 24, 273-278. https://doi.org/10.1111/j.1600-0838.2012.01458.x

Ferrari, G., Araujo, L., Oliveira, L., Matsudo, V., Mire, E. et al. (2015). Association between Television Viewing and Physical Activity in 10-Year-Old Brazilian Children. Journal of Physical Activity \& Health, 12, 1401-1408. https://doi.org/10.1123/jpah.2014-0406

Förster, H. (2005). Messung der körperlichen Aktivität und der körperlichen Leistungsfähigkeit. In M. Wabitsch, K. Zwiauer, J. Hebebrandt, \& W. Kies (Eds.), Adipositas bei Kindern und Jugendlichen (pp. 277-282). Berlin: Springer.

https://doi.org/10.1007/3-540-26775-1_34 
Greier, K. (2013). Empirische Forschung zur Täglichen Sportstunde. Ergebnisdarstellung ausgewählter nationaler und internationaler Studien. Erziehung \& Unterricht, 7-8, 665-672.

Greier, K., \& Drenowatz, C. (2018). Bidirectional Association between Weight Status and Motor Skills in Adolescents. Wiener Klinische Wochenschrift, 1, 1-7.

Greier, K., Drenowatz, C., Ruedl, G., Lackner, C., Kroell, K. et al. (2018). Differences in Motor Competence by TV Consumption and Participation in Club Sports in Children Starting Elementary School. International Journal of School Health, 5, e68454. https://doi.org/10.5812/intjsh.68454

Greier, K., Riechelmann, H., Ruedl, G., \& Drenowatz, C. (2019). Changes in Motor Competence over Four Decades in 10 to 14-Year-Old Austrian Boys. Current Issues in Sport Science, 4, 1-8. https://doi.org/10.15203/CISS_2019.012

Guthold, R., Stevens, G. A., Riley, L. M., \& Bull, F. C. (2020). Global Trends in Insufficient Physical Activity among Adolescents: A Pooled Analysis of 298 Population-Based Surveys with 1.6 Million Participants. The Lancet Child \& Adolescent Health, 4, 23-35. https://doi.org/10.1016/S2352-4642(19)30323-2

Hardy, L., Barnett, L., Espinel, P., \& Okely, A. (2013). Thirteen-Year Trends in Child and Adolescent Fundamental Movement Skills: 1997-2010. Medicine \& Science in Sports \& Exercise, 45, 1965-1970. https://doi.org/10.1249/MSS.0b013e318295a9fc

Houston, E. L., Baker, J. S., Buchan, D. S., Stratton, G., Fairclough, S. J. et al. (2013). Cardiorespiratory Fitness Predicts Clustered Cardiometabolic Risk in 10-11.9-Year-Olds. European Journal of Pediatrics, 172, 913-918.

https://doi.org/10.1007/s00431-013-1973-z

Janssen, I., \& Leblanc, A. (2010). Systematic Review of the Health Benefits of Physical Activity and Fitness in School-Aged Children and Youth. International Journal of Behavioral Nutrition and Physical Activity, 7, 40. https://doi.org/10.1186/1479-5868-7-40

Kaiser-Jovy, S., Scheu, A., \& Greier, K. (2017). Media Use, Sports Activities and Motor Fitness in Childhood and Adolescence. Wiener Klinische Wochenschrift, 129, 464-471. https://doi.org/10.1007/s00508-017-1216-9

Logan, S. W., Robinson, L. E., Wilson, A. E., \& Lucas, W. A. (2012). Getting the Fundamentals of Movement: A Meta-Analysis of the Effectiveness of Motor Skill Interventions in Children. Child: Care, Health and Development, 38, 305-315.

https://doi.org/10.1111/j.1365-2214.2011.01307.x

Mathers, M., Canterford, L., Olds, T., Hesketh, K., Ridley, K. et al. (2009). Electronic Media Use and Adolescent Health and Well-Being: Crosssectional Community Study. Academic Pediatrics, 9, 307-314. https://doi.org/10.1016/j.acap.2009.04.003

Muellerova, D., Langmajerova, J., Sedlacek, P., Dvorakova, J., Hirschner et al. (2015). Dramatic Decrease in Muscular Fitness in Czech Schoolchildren over the Last 20 Years. Central European Journal of Public Health, 23, 9-13.

https://doi.org/10.21101/cejph.a4069

Myers, J., Prakash, M., Froelicher, V., Partington, S., \& Atwood, J. (2002). Exercise Capacity and Mortality among Men Referred for Exercise Testing. The New England Journal of Medicine, 346, 793-801. https://doi.org/10.1056/NEJMoa011858

Obst, F., \& Bös, K. (1998). Mehr Unterrichtszeit im Schulsport: Die tägliche Sportstunde. Sportpädagogik, 22, 12-14.

Ortega, F., Ruiz, J., Castillo, M., \& Sjöström, M. (2008). Physical Fitness in Childhood and Adolescence: A Powerful Marker of Health. International Journal of Obesity, 32, 1-11. https://doi.org/10.1038/sj.ijo.0803774 
Osterroth, A., Spang, F., \& Gießing, J. (2012). Die kurzfristigen physiologischen Auswirkungen einer täglichen Sportstunde. Ergebnisse einer Pilotstudie mit Schülerinnen und Schülern einer vierten Klasse. Sportunterricht, 61, 14-19.

Owen, N., Healy, G., Matthews, C., \& Dunstan, D. (2010). Too Much Sitting: The Population Health Science of Sedentary Behavior. Exercise and Sport Sciences Reviews, 38, 105-113. https://doi.org/10.1097/JES.0b013e3181e373a2

Reilly, J. J., Jackson, D. M., Montgomery, C., Kelly, L. A., Slater, C. et al. (2004). Total Energy Expenditure and Physical Activity in Young Scottish Children: Mixed Longitudinal Study. The Lancet, 363, 211-212. https://doi.org/10.1016/S0140-6736(03)15331-7

Riethmuller, A. M., Jones, R., \& Okely, A. D. (2009). Efficacy of Interventions to Improve Motor Development in Young Children: A Systematic Review. Pediatrics, 124, e782-e792. https://doi.org/10.1542/peds.2009-0333

Ruedl, G., Greier, K., Kirschner, W., \& Kopp, M. (2016). Factors Associated with Motor Performance among Overweight and Nonoverweight Tyrolean Primary School Children. Wiener Klinische Wochenschrift, 128, 14-19. https://doi.org/10.1007/s00508-015-0887-3

Seyda, M. (2011). Methodisches Vorgehen. Untersuchungsdesing und-stichproben. In J. Thiele, \& M. Seyda (Eds.), Tägliche Sportstunde an Grundschulen in NRW. Modelle-Umsetzungen-Ergebnisse (pp. 53-57). Aachen: Meyer \& Meyer.

Tomkinson, G. R., Léger, L. A., Olds, T. S., \& Cazorla, G. (2003). Secular Trends in the Performance of Children and Adolescents (1980-2000): An Analysis of 55 Studies of the 20m Shuttle Run Test in 11 Countries. Sports Medicine, 33, 285-300. https://doi.org/10.2165/00007256-200333040-00003

Tomkinson, G., \& Olds, T. (2007). Secular Changes in Pediatric Aerobic Fitness Test Performance: The Global Picture. Medicine and Sport Science, 50, 46-66. https://doi.org/10.1159/000101075

Vandorpe, B., Vandendriessche, J., Vaeyens, R., Pion, J., Matthys, S. et al. (2012). Relationship between Sports Participation and the Level of Motor Coordination in Childhood: A Longitudinal Approach. Journal of Science and Medicine in Sport, 15, 220-225. https://doi.org/10.1016/j.jsams.2011.09.006

World Health Organisation WHO (2016). Growing Up Unequal: Gender and Socioeconomic Differences in Young People's Health and Well-Being. Health Behavior in School-Aged Children (NBSC) Study. Copenhagen: WHO Regional Office for Europe. 